\title{
Students' e-Learning System Usage Outcomes: A Study with a Learning Management System
}

\author{
A.K.M. Najmul Islam \\ Turku Center for Computer Science (TUCS), University of Turku, Finland \\ najmul.islamatse.fi
}

\begin{abstract}
E-learning systems such as the learning management systems are widely used in higher education. However, much of the research on e-learning systems focuses on the technology and is limited to the adoption and utilization e-learning systems. In order to develop the potential advantages of e-learning systems, research that addresses the outcomes of the adoption and use of elearning system is needed. This paper proposes a research model for assessing the possible outcomes of learning management systems adoption and use. It was tested by university students $(\mathrm{n}=249)$ participating in hybrid courses using partial least squares (PLS) analysis. Its findings suggest that beliefs about perceived usefulness and perceived ease of use, and how an e-learning system is used assist students' perceived learning and perceived community building.
\end{abstract}

Keywords: e-learning system use, learning management system, technology acceptance model, use outcomes.

\section{Introduction}

One of the most significant developments in the use of information technology in universities in the last decade has been the adoption and use of e-learning systems to support the processes of teaching and learning. The learning management system (LMS), also known as course management system (CMS) or the virtual learning environment (VLE), is an e-learning system that has been widely adopted by universities. The LMS is web-based software that is used for the delivery, tracking and managing of education and training online. It contains features for distributing courses over the Internet and online collaboration. Since the late 1990s, the utilization of LMSs for online education has steadily increased in higher education. Nowadays, LMSs have become indispensable tools for online education. Whether focusing on distance education or class-room based education, most universities use LMSs to support and improve learning and teaching processes [1]. For example, in 2005, 95\% of all higher education institutions in the UK used course management systems [2]. LMSs are usually implemented across an entire university, faculty, or school, and then adopted by educators who use them in a variety of ways to support course management and student learning [3]. The use of the LMSs in university education has made it easy to augment online education with traditional face-to-face classroom instruction. Such a hybrid or mixed delivery approach allows educators to combine 
the advantages of online learning with the benefits of face-to-face instruction [4]. A mix of face-to-face (somewhere between $90 \%$ and 10\%) and online instruction (somewhere between $10 \%$ and $90 \%$ ) has been argued to be superior to either $100 \%$ face-to-face or $100 \%$ online courses [31].

However, in order to understand the impact of e-learning systems on students' learning outcomes and take advantage of the potential of e-learning systems, research that addresses the role of e-learning systems adoption and its use in learning outcomes is needed. In addition, research investigating the factors that influence the adoption and use of e-learning systems is required - if we are to further develop e-learning systems. There has been much prior research focusing on the adoption and use of elearning systems $[5 ; 6]$. These studies identified the e-learning system usage intention as the dependent variable and investigated its antecedents or determinants. However, these studies overlooked the outcomes of e-learning system usage. Knowing the outcomes of e-learning system usage is particularly important if we are to evaluate the success of such systems, plan for their future development and achieve better learning outcomes. Thus, this paper investigates the outcomes of e-learning system usage for hybrid courses from the perspective of university students.

The paper proceeds as follows. In section 2 we present the literature review and research model. Section 3 is dedicated to the research method and section 4 presents the data analysis results and discussion. Finally, section 5 discusses the implications.

\section{$2 \quad$ Literature Review and Research Model}

One of the major focuses of prior e-learning research has been the adoption and continued use of e-learning systems [5;6]. This research stream has mainly used two theoretical frameworks: the technology acceptance model (TAM) [7] and the expectation-confirmation model (ECM) [8] to investigate individuals' e-learning system adoption and continued use. These studies mainly investigated the factors that affect the adoption and use of e-learning systems, but they do not consider how these factors, or the use of the e-learning system itself is associated with learning outcomes. Indeed, few studies have gone beyond use to explore the factors associated with learning. McGill and Klobas [3] found that e-learning system utilization influences the perceived impact on learning. Lee and Lee [9] revealed that a number of elearning environment quality related variables affect satisfaction with e-learning. In turn, satisfaction was found to influence academic achievement. Liaw [10] found high correlation between intention to use e-learning and e-learning effectiveness. These studies provide some empirical support about the possible relationships between elearning system use and e-learning system usage outcomes. However, these studies have been conducted with a variety of outcome variables that use different explanatory variables and this has led to models that offer only weak theoretical support. Thus, these studies fall short in explaining the relationship between the antecedents of adoption and use of e-learning systems and their use outcomes, and the relationship between e-learning system use and use outcomes. Hence, a conceptual framework with strong theoretical support is necessary. 
Fig. 1 illustrates the conceptual framework of the e-learning system use outcomes.

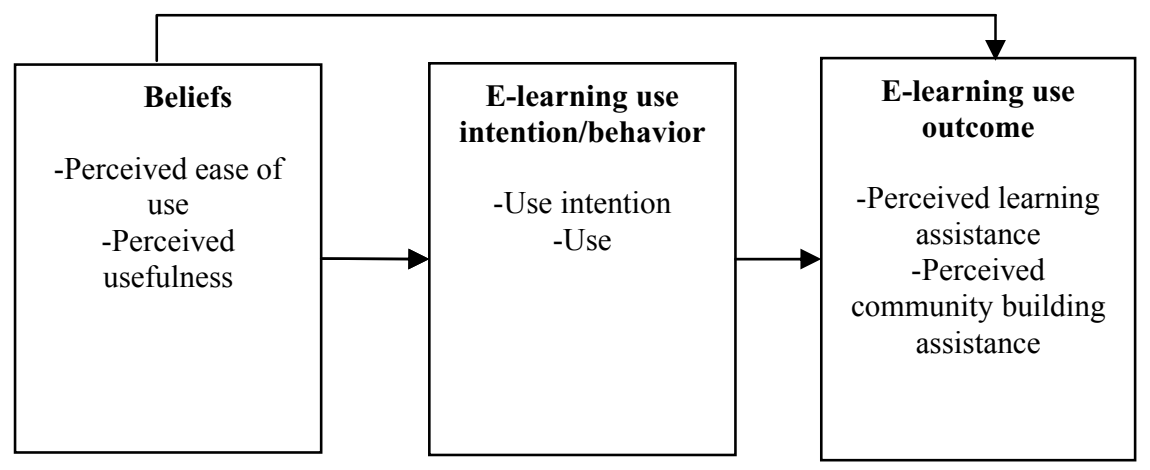

Fig. 1. Conceptual framework for e-learning system use outcome

The framework is conceptually supported by both the IS adoption model, TAM [7] and the IS success model [11]. TAM presents two behavioral beliefs, perceived usefulness and perceived ease of use as the antecedents of IS usage intention and use. Perceived usefulness is the degree to which an individual believes that the system will enhance his or her job performance and perceived ease of use is defined as the degree to which a person believes that using a system would be free of effort [7]. Following TAM, we posit that these two behavioral beliefs result in e-learning system use. On the other hand, according to the IS success model, IS use brings benefits to both individuals and organizations [11]. Similarly, according to our framework, e-learning system use will positively affect the learning process of individuals. In particular, we argue that two variables regarding individuals' learning processes, perceived learning assistance and perceived community building assistance, are important. Perceived learning assistance refers to the extent to which the e-learning system assists an individual's learning while perceived community building assistance refers to the extent to which the e-learning system assists individuals in building a social community.

In summary, according to this framework, beliefs may impact on e-learning use outcomes in two ways. First, the beliefs can have a direct impact on e-learning use outcome variables. For example, a useful and/or easy to use e-learning system may assist students by helping them to learn more effectively and by giving them an opportunity to build a social network. Such benefits may help students improve their academic performance. The direct relationship between the beliefs and e-learning use outcomes are supported by a number of prior studies [3; 9]. Second, these beliefs can have an indirect effect on e-learning use outcomes through the mediation of elearning system use. As described earlier, this indirect effect is supported by the IS success model.

Based on the conceptual framework, we have developed a research model for evaluating how the use of an e-learning system affects e-learning outcomes. The research model is shown in Fig. 2. 


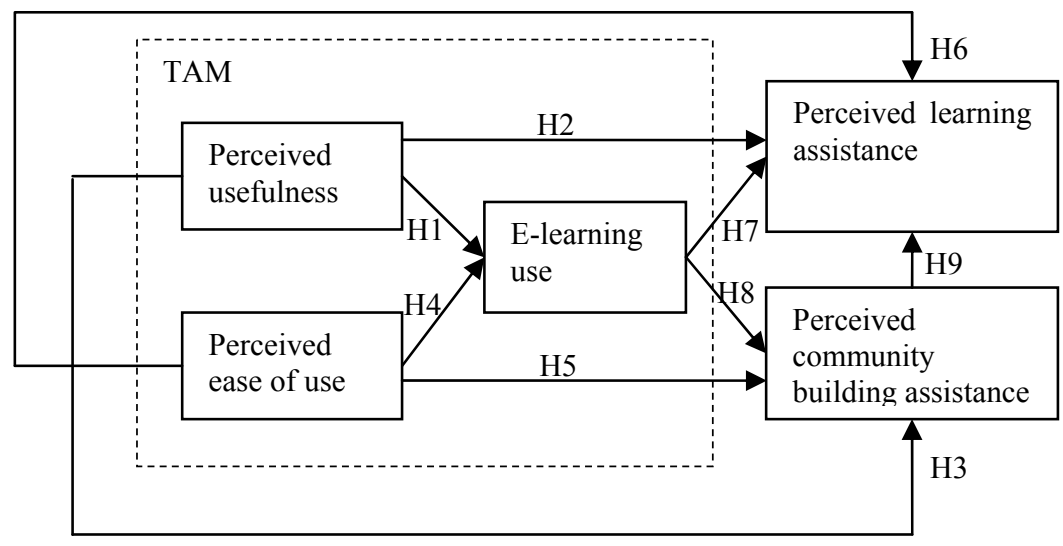

Fig. 2. Research model

TAM postulates that perceived usefulness has an impact on IS use. If individuals believe that the e-learning system they use provides them with better information or increased learning control, they are more likely to use the system in the courses for reading and downloading learning materials and interacting with other participants (participating in the discussions, chatting, emailing, etc.). The association between perceived usefulness and e-learning system use is supported by many prior studies [5; 6]. Thus, we make the following hypothesis.

H1. Perceived usefulness positively affects students' e-learning system use.

A particular e-learning system can provide value in several ways [12]. First, the system can be more useful when it expands either the quality or quantity of information which the students are able to access. Second, the e-learning system can be useful because it helps the students manage and control their learning process. Prior studies have argued that greater learning control by students leads to better learning outcomes [13; 14], which suggests that a useful e-learning system may increase students' control of the learning process and eventually affect learning effectiveness. In addition, the e-learning system can be useful because it contains many features that help the participants collaborate with each other. Thus, we propose the following two hypotheses.

H2. Perceived usefulness positively affects students' perceived learning assistance.

H3. Perceived usefulness positively affects students' perceived community building assistance.

TAM further postulates that perceived ease of use affects IS use. It has been confirmed by many studies in different contexts including e-learning system utilization $[5 ; 32]$. Thus, we propose the following hypothesis.

H4. Perceived ease of use positively affects students' e-learning system use.

We further argue that an easy to use e-learning system may assist students' learning and help to build a collaborative community. The technical design and format will impact on how effectively the participants can share learning materials 
and collaborate with each other [36]. In addition, when the students perceive an elearning system as easy to use, they are better able to concentrate on their learning instead of putting effort into learning the system itself. The system provides them with an easy way to collaborate with others, which eases the group work. Following this, we propose the following two hypotheses.

H5. Perceived ease of use positively affects students' perceived learning assistance.

H6. Perceived ease of use positively affects students' perceived community building assistance.

Although, students and educators are physically separated in an e-learning environment, it has been argued that students' engagement is greatly increased in such a learning environment [15]. Increased student engagement can improve learning outcomes, such as problem solving and critical thinking skills [16]. Individuals are assumed to learn better when they discover things by themselves and when they control the pace of learning [17]. This implies that the use of e-learning systems in the courses provides some sort of self-directed learning opportunities which lead to the improvement of learning effectiveness among the students. The studies built upon social network theory argue that students interact more effectively when a social structure enables them to access a larger base of contacts and makes the exchange of information faster [33; 34]. Fast receipt of information may assist learning. For example, educators can upload learning materials in advance so that the students can read them before going to class. This may allow them to learn effectively in classroom situations. In addition, both educators and students can instantly share other course related information by utilizing the database of contacts. They may also use chat or discussion facilities for immediate and fast communication. Thus, it is plausible to assume that the utilization of the e-learning systems provides the opportunity to share information faster. Thus, we propose the following hypothesis.

H7. Use of an e-learning system in a course positively affects students' perceived learning assistance.

Studies suggest that an effectively designed and administered online course environment can assist in the creation of a social environment [18]. We further argue that such social interaction will create a social network. For example, face-to-face meetings among educators and students should help to build a supportive social network. Additionally, online activities should provide students with the opportunity to become better acquainted and share their common interests about a particular topic more deeply. It may even be that many students become more active in the online social medium of instruction in comparison with face-to-face situations. In fact, some students may prefer to participate more in online discussions rather than face-to-face. In brief, active online discussions conducted by students may allow them to create a network with both educators and other students. Thus, we propose the following hypothesis.

H8. Use of an e-learning system in a course positively affects students' perceived community building assistance.

Lastly, research on the learning processes in face-to-face groups indicates that the development of social community is important for making students feel like insiders in the learning environment, thus contributing to students' motivation, involvement, and contentment [19]. Following this, we propose the following hypothesis.

H9. Perceived community building assistance positively affects students' perceived learning assistance. 


\section{Research Method}

\subsection{Questionnaire Development}

The questionnaire had three parts: demographic questions, questions related to the constructs of the research model, and open ended questions asking to report the students' satisfaction and dissatisfaction with the target system. Each item corresponding to the constructs has been measured using the seven-point Likert scale, the answer choices range from "Strongly disagree (1)" to "Strongly agree (7)". Most of these items are adapted from the literature with minor changes in wording reflecting the target system. The measures of perceived usefulness and e-learning system use were adapted from Limayem et al. [22] and Ma et al. [23] respectively. The measures of perceived ease of use were adapted from Hong et al. [24]. The measures of perceived learning assistance were developed from Liaw [10]. Finally, the measures of perceived community building assistance were developed from Paechter et al. [25]. After the questionnaire was drafted, it was first sent to two academic researchers for their review and revised according to their comments and suggestions to make the wording of the items more precise. Then, the questionnaire was sent to 10 students for their review. Overall, the students indicated that the questionnaire was relatively clear and easy to complete. A number of suggestions were made concerning the wording of several items and the overall structure of the questionnaire. The questionnaire was revised according to the given suggestions. In order to avoid the common method bias problem as much as possible, we decided to randomize the questions in the questionnaire during data collection [26].

\subsection{Participants}

The target system of this study is the learning management system, Moodle (http://moodle.org/about/). Moodle is an open source course management system and has become very popular among educators for creating dynamic online course websites for students. Moodle can be used to conduct online courses or to augment face-to-face courses (hybrid courses).

This study was conducted in an internationally acknowledged, multidisciplinary scientific university in Finland. The university has seven faculties. The university has been using Moodle since 2007 as its platform for creating course pages online. Data was collected via a web-based survey from the students of the university who use Moodle in hybrid courses. A list of students' email addresses was collected from the Moodle support team in the university. A total of 1100 email invitations were sent to randomly selected students of the university who had been registered in Moodle as student users. One reminder was sent to increase the response rate after a gap of one week. The survey ran for approximately two weeks. After filtering invalid and incomplete responses, we had a total of 249 survey responses that could be used in this study. The demographic information of the respondents is given in Table 1. 
Table 1. Demographic information

\begin{tabular}{llll}
\hline & & Frequency & Percentage \\
\hline Gender & Male & 101 & 40.56 \\
& Female & 148 & 59.44 \\
Age & less than 21 years & 31 & \\
& 21-30 years & 166 & 12.45 \\
& 31-40 years & 25 & 66.67 \\
& $>$ 41 years & 27 & 10.04 \\
& & & 10.84 \\
Experience with the target & 0 - 6 months & 15 & \\
& $>6$ months -1 year & 63 & 6.02 \\
& $>1$ year -1 year 6 months & 10 & 25.30 \\
& $>1$ year 6 months -2 years & 47 & 18.02 \\
& $>2$ years -2 years 6 months & 9 & 3.61 \\
& $>2$ years 6 months -3 years & 27 & 10.84 \\
& $>3$ years & 78 & 31.33 \\
\hline
\end{tabular}

\subsection{Data Analysis}

To analyze the quantitative data, we employed partial least squares (PLS) as our analysis approach and utilized the tool smartPLS [27]. PLS is a second generation regression method that combines confirmatory factor analysis with linear regression, and this makes it possible to run the measurement and structural models simultaneously. The qualitative data was content analyzed and used to support the findings of the PLS model.

Table 2 shows item wise averages and the loadings of each construct in the model. For each construct the assessment of convergent validity or internal consistency is also included through the composite reliability coefficient [28]. Convergent validity indicates the extent to which the items of a scale that are theoretically related are also related in reality. As we can see from Table 2, all items have significant path loadings greater than the threshold 0.7 recommended Fornell and Larcker [28]. All the constructs have composite reliability values that exceed the threshold recommended by Nunnally [29].

Testing for discriminant validity involves checking whether the items measure the construct in question or other (related) constructs. Discriminant validity was verified with both correlation analysis and factor analysis as recommended by Gefen and Straub [30]. First, the inspection of discriminant validity among variables is based on the correlation between variables and the square root of their respective average variance extracted [28]. As Table 3 shows, the square root of the average variance extracted value for the variables is consistently greater than the off-diagonal correlation values, suggesting satisfactory discriminant validity between the variables. Second, from Table 4 we see that all items have cross loadings coefficients lower than the factor loading on their respective assigned latent variable, suggesting that discriminant validity on the item level is met for all the constructs. 
Table 2. Construct items, means and internal consistencies

\begin{tabular}{|c|c|c|c|c|}
\hline Construct & Item & Mean & std & Loading \\
\hline \multirow{3}{*}{$\begin{array}{l}\text { Perceived } \\
\text { usefulness }(\mathrm{CR} \\
=0.91 ; \mathrm{AVE}= \\
0.76)\end{array}$} & PU-1: Using Moodle is of benefit to me & 5.33 & 1.46 & $0.87 *$ \\
\hline & $\begin{array}{l}\text { PU-2: The advantages of Moodle } \\
\text { outweigh the disadvantages }\end{array}$ & 5.37 & 1.38 & $0.91 *$ \\
\hline & $\begin{array}{l}\text { PU-3: Overall, using Moodle is } \\
\text { advantageous }\end{array}$ & 5.32 & 1.71 & $0.84 *$ \\
\hline $\begin{array}{l}\text { Perceived ease } \\
\text { of use }(\mathrm{CR}=\end{array}$ & $\begin{array}{l}\text { PEOU-1: My interaction with Moodle is } \\
\text { clear and understandable }\end{array}$ & 4.90 & 1.39 & $0.86^{*}$ \\
\hline \multirow[t]{3}{*}{$\begin{array}{l}0.93 ; \text { AVE }= \\
0.77)\end{array}$} & $\begin{array}{l}\text { PEOU-2: Interacting with Moodle does } \\
\text { not require a lot of mental effort }\end{array}$ & 5.15 & 1.51 & $0.87 *$ \\
\hline & PEOU-3: I find Moodle to be easy to use & 5.16 & 1.54 & $0.90 *$ \\
\hline & $\begin{array}{l}\text { PEOU-4: I find it easy to get Moodle to } \\
\text { do what I want to do }\end{array}$ & 4.76 & 1.51 & $0.88 *$ \\
\hline \multirow{4}{*}{$\begin{array}{l}\text { Perceived } \\
\text { learning } \\
\text { assistance }(\mathrm{CR} \\
=0.93 ; \mathrm{AVE}= \\
0.76)\end{array}$} & $\begin{array}{l}\text { PLA-1: Moodle provides flexibility of } \\
\text { learning with regard to time and place }\end{array}$ & 5.67 & 1.38 & $0.81 *$ \\
\hline & $\begin{array}{l}\text { PLA-2: Moodle assists learning } \\
\text { performance }\end{array}$ & 4.84 & 1.37 & $0.93 *$ \\
\hline & PLA-3: Moodle assists learning efficiency & 4.76 & 1.46 & $0.92 *$ \\
\hline & $\begin{array}{l}\text { PLA-4: Moodle assists learning } \\
\text { motivation }\end{array}$ & 4.31 & 1.54 & $0.83 *$ \\
\hline $\begin{array}{l}\text { Perceived } \\
\text { community }\end{array}$ & $\begin{array}{l}\text { PCB-1: Moodle provides opportunities to } \\
\text { establish personal contact with teachers }\end{array}$ & 3.97 & 1.76 & $0.82 *$ \\
\hline $\begin{array}{l}\text { building } \\
\text { assistance }(\mathrm{CR}\end{array}$ & $\begin{array}{l}\text { PCB-2: Moodle makes it easy to do group } \\
\text { work }\end{array}$ & 3.88 & 1.57 & $0.88^{*}$ \\
\hline $\begin{array}{l}=0.89 ; \mathrm{AVE}= \\
0.72)\end{array}$ & $\begin{array}{l}\text { PCB-3: Moodle provides opportunities to } \\
\text { establish new contacts with other students }\end{array}$ & 3.35 & 1.57 & $0.85 *$ \\
\hline $\begin{array}{l}\text { E-learning } \\
\text { system use (CR }\end{array}$ & $\begin{array}{l}\text { USE-1: I use Moodle frequently in this } \\
\text { academic period }\end{array}$ & 4.82 & 1.65 & $0.96^{*}$ \\
\hline $\begin{array}{l}=0.96 ; \mathrm{AVE}= \\
0.92)\end{array}$ & $\begin{array}{l}\text { USE-2: I use Moodle heavily during my } \\
\text { study }\end{array}$ & 4.20 & 1.58 & $0.96^{*}$ \\
\hline
\end{tabular}

Note: Composite reliability (CR), Average Variance Extracted (AVE), ${ }^{*} \mathrm{p}<0.001$

Table 3. Correlation between the variables and squared root of average variance extracted

\begin{tabular}{llllll}
\hline & PLA & PEOU & PU & PCB & USE \\
\hline PLA & $\mathbf{0 . 8 7}$ & & & & \\
PEOU & 0.57 & $\mathbf{0 . 8 8}$ & & & \\
PU & 0.68 & 0.65 & $\mathbf{0 . 8 7}$ & & \\
PCB & 0.60 & 0.36 & 0.45 & $\mathbf{0 . 8 5}$ & \\
USE & 0.60 & 0.60 & 0.70 & 0.40 & $\mathbf{0 . 9 6}$ \\
\hline
\end{tabular}

Note: Perceived learning assistance (PLA), Perceived ease of use (PEOU), Perceived usefulness (PU), Perceived community building assistance (PCB). 
Table 4. Factor analysis results

\begin{tabular}{llllll}
\hline & PLA & PEOU & PU & PCB & USE \\
\hline PLA-1 & $\mathbf{0 . 8 1 1 7 0 3}$ & 0.558073 & 0.648265 & 0.477433 & 0.537861 \\
PLA-2 & $\mathbf{0 . 9 2 9 2 2 5}$ & 0.521947 & 0.594350 & 0.519992 & 0.529865 \\
PLA-3 & $\mathbf{0 . 9 2 0 7 2 1}$ & 0.501885 & 0.615953 & 0.478445 & 0.521858 \\
PLA-4 & $\mathbf{0 . 8 2 7 8 6 3}$ & 0.427086 & 0.520408 & 0.597071 & 0.509509 \\
PEOU-1 & 0.526706 & $\mathbf{0 . 8 6 0 3 8 9}$ & 0.619708 & 0.375455 & 0.567165 \\
PEOU-2 & 0.420433 & $\mathbf{0 . 8 6 7 0 5 4}$ & 0.503426 & 0.230550 & 0.446315 \\
PEOU-3 & 0.501233 & $\mathbf{0 . 8 9 6 6 2 4}$ & 0.582400 & 0.295034 & 0.543351 \\
PEOU-4 & 0.546963 & $\mathbf{0 . 8 7 6 3 5 6}$ & 0.569808 & 0.355136 & 0.518067 \\
PU-1 & 0.629898 & 0.577446 & $\mathbf{0 . 8 6 9 6 9 6}$ & 0.413334 & 0.624178 \\
PU-2 & 0.591721 & 0.602227 & $\mathbf{0 . 9 1 0 3 3 1}$ & 0.402224 & 0.645901 \\
PU-3 & 0.556769 & 0.531375 & $\mathbf{0 . 8 3 8 6 6 3}$ & 0.351760 & 0.570731 \\
PCB-1 & 0.440082 & 0.212962 & 0.359335 & $\mathbf{0 . 8 1 9 0 3 1}$ & 0.343828 \\
PCB-2 & 0.581021 & 0.415652 & 0.448503 & $\mathbf{0 . 8 7 5 9 9 7}$ & 0.379125 \\
PCB-3 & 0.480850 & 0.274310 & 0.317311 & $\mathbf{0 . 8 5 2 9 1 0}$ & 0.300786 \\
USE-1 & 0.577935 & 0.563957 & 0.672974 & 0.380150 & $\mathbf{0 . 9 5 6 6 9 9}$ \\
USE-2 & 0.571949 & 0.578858 & 0.673771 & 0.392885 & $\mathbf{0 . 9 5 7 1 8 4}$ \\
\hline
\end{tabular}

Note: Perceived learning assistance (PLA), Perceived ease of use (PEOU), Perceived usefulness (PU), Perceived community building assistance (PCB).

\section{$4 \quad$ Results and Discussions}

The test of the structural model includes estimates of the path coefficients, which indicates the strengths of the relationships between the dependent and independent variables, and the R-square values, which represent the amount of variance explained by the independent variables. Fig. 3 shows the results of the test of the hypothesized model.

Use antecedents Use Use outcomes

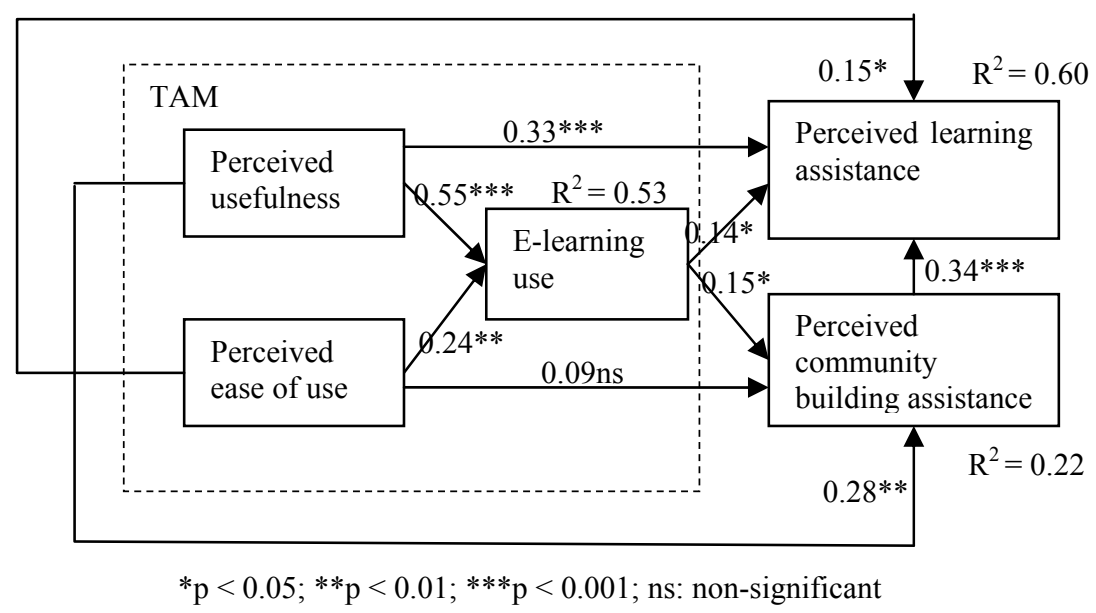

Fig. 3. PLS Model results 
As hypothesized, perceived usefulness ( $\beta=0.55 ; \mathrm{p}<0.001$ ) and perceived ease of use $(\beta=0.24 ; p<0.01)$ have a significant impact on e-learning use explaining its $53 \%$ variance. On the other hand, perceived usefulness $(\beta=0.33 ; \mathrm{p}<0.001)$, e-learning use $(\beta=0.14 ; p<0.05)$, perceived ease of use $(\beta=0.15 ; p<0.05)$, and perceived community building assistance $(\beta=0.34 ; \mathrm{p}<0.001)$ have significant effects on perceived learning assistance explaining its $60 \%$ variance. Perceived usefulness $(\beta=$ $0.28 ; \mathrm{p}<0.01)$ and e-learning use $(\beta=0.15 ; \mathrm{p}<0.05)$ were also found to have a significant impact on perceived community building assistance.

The relationships of the TAM model were supported in our study. As expected, perceived usefulness affects e-learning use significantly. This finding is in line with the findings of [8]. The qualitative data also supported this finding. For example, one student wrote the following:

\section{"....Finding all course materials in one place is great...."}

In addition, we found that perceived ease of use also predicts e-learning use significantly. However, its predictive strength is weaker than perceived usefulness. This finding is in line with those of IS adoption studies [7].

The other hypotheses are discussed below. First, our study results revealed that perceived usefulness strongly impacts on both perceived learning assistance and perceived community building assistance. These relationships were not tested empirically in the prior studies. However, the findings of prior studies provide indirect empirical support for our findings. Johnson et al. [12] conceptualized course performance, course satisfaction and course instrumentality as the measures of elearning effectiveness. They concluded that perceived usefulness has a significant impact on both course performance and course satisfaction. Our finding is also indirectly supported by media synchronicity theory [35]. Media synchronicity theory emphasizes three key features of a media that enable effective communication: parallelism, reprocessibility and rehearsability [35]. Parallelism refers to the medium's capability to support multiple and simultaneous conversations. Reprocessibility refers to the medium's capability to support the reexamining and revisiting of a message. Finally, rehearsability refers to the medium's capability of supporting reediting and refining a message before sending it out. The LMSs provide such facilities, of which the group discussions facility in the e-learning systems is an excellent example. Additional examples include the ability to have multiple conversations, documenting conversation history for future reference, and editing a message before sending it. Thus, our finding about the association between perceived usefulness and perceived learning assistance is in line with the prior literature. The qualitative data also provides support for our findings. For example, one student wrote the following:

“....For one course, we had good group discussion on Moodle. The topic was good, and all the students participated and Moodle worked well which made me inspired by the course and assignment in general...."

In addition, Dourish, and Bly [37] have examined how synchronous and asynchronous computer mediated communication (CMC) tools deliver and support social awareness. They found the successful delivery of social awareness via the 
CMC tools resulted in a sense of community through the maintaining of working relationships and informal communication. Thus, our finding about the association between perceived usefulness and perceived community building assistance is in line with prior findings.

Second, we found that perceived ease of use was also significant - although very weak - in predicting perceived learning assistance. In addition, we observed that it had a non-significant impact on perceived community building assistance. We argue that the weak and non-significant impacts can be explained based on prior findings. In particular, adoption studies argue that perceived ease of use is weak at predicting the usage intention for experienced users [7]. In our study, the respondents were experienced with the target system (see Table 1). Thus, perceived ease of use did not contribute strongly to predicting perceived learning assistance and perceived community building assistance.

Third, we found that e-learning system use also has a significant direct impact (although very weak) on both perceived learning assistance and perceived community building assistance. These causal relationships have not been tested empirically in prior literature, although there is ample evidence of support for this finding. For example, it is often argued that replacing some of the in-class activities with elearning resulted in higher learning outcomes when compared to traditional face-toface learning. Empirically, Liaw [10] found a high correlation between e-learning utilization intention and e-learning effectiveness. In addition, McGill and Klobas [3] found LMS use positively affects students' perceived learning impact. On the other hand, several studies found that students are inclined to explore new social ties and links when they participate in Computer Supported Collaborative Learning (CSCL) environment [33]. Thus, we conclude that our findings are supported by prior findings. However, the interesting point is that we found e-learning use is very weak at predicting both learning assistance and community building assistance. The interpretation of this finding is that the extensive use of e-learning system does not necessarily bring benefits to students. Hence e-learning systems should be used in such a way that can help to learn and increase collaboration. Such effective utilization largely depends on an educator's capabilities to build an effective learning environment with the students. The qualitative data provides further support to this. For example, one student wrote the following:

“....All teachers do not know how to use Moodle, some teachers know but they don't take the full advantage of Moodle...."

Another student wrote the following:

\section{"....Moodle sites work best when the teachers put timely and valuable information there...."}

Another student wrote the following:

"....I have the feeling that teachers do not really want us to take full advantage of Moodle. For example, the teachers do not really encourage us to use discussion forums. In addition they do not allow us to put external links to the Moodle page which could be important for learning...." 
Finally, perceived community building assistance impacts on perceived learning assistance. This finding is also in line with prior studies indirectly. For example, a number of studies found that building a sense of community is necessary for successful learning outcomes [19; 31]. It suggests that the use of e-learning systems helps students to build a social network with teachers and other students, which leads to more effective learning.

\section{Implications}

Our study findings have a major theoretical implication. Our study has found how TAM variables affect e-learning usage outcomes. While prior studies only investigated the adoption and use of e-learning systems, our study went beyond elearning use and provided insights into the outcomes of e-learning system adoption and use. Overall, the study's findings suggest that an e-learning system may assist students in learning and building a collaborative network, if it is used to augment face-to-face education.

Our study findings have practical implications for e-learning system designers, educators, and school management. First, the study found that behavioral beliefs (perceived usefulness and perceived ease of use) have significant impacts on perceived learning assistance and perceived community building assistance, which implies that designers need to develop e-learning systems that are useful and easy to use in order to affect students' learning outcomes. Developing easy to use and useful systems also leads to more usage of such systems by students. However, educators need to remember that the increased usage of e-learning systems may not lead to more effective learning and better community building. Educators are required to put effort into designing courses utilizing e-learning systems so that the students are able to learn effectively. They should add different functionalities to the course pages and encourage the students to use them. For example, educators may encourage the students to participate in the discussion forums. They may announce some incentive, such as the possibility to earn some bonus points for active participation.

Finally, an education institute's management needs to know how to ensure users' effective usage of e-learning systems. Improving students' and educators' knowledge about the e-learning systems should lead to the effective usage of such systems. If they do not have much knowledge of these systems, they are less likely to use them or they may not be able to gain the full benefits of such systems, which may result in ineffective online collaboration. In turn, ineffective collaboration may negatively impact on student learning. Therefore, schools and universities should provide training for both students and educators on how to use their particular e-learning systems most effectively.

\section{References}

1. Dalsgaard, C.: Social software: E-learning beyond learning management systems. European Journal of Open, Distance and E-learning (2006), http: / /www. eurodl.org/materials/contrib/2006/Christian_Dalsg aard.pdf (retrieved March 26, 2011) 
2. Browne, T., Jenkins, M., Walker, R.: A longitudinal perspective regarding the use of VLEs by higher education institutions in the United Kingdom. Interactive Learning Environments 14(2), 177-192 (2006)

3. McGill, T.J., Klobas, J.E.: A task-technology fit view of learning management system impact. Computers \& Education 52, 496-508 (2009)

4. Edling, R.J.: Information Technology in the classroom: Experiences and recommendations. Campus Wide Information Systems 17(1), 10-15 (2000)

5. Islam, A.K.M.N.: Understanding continued usage intention in e-learning context. In: 24th Bled eConference AIS e-library, Slovenia (2011)

6. Islam, A.K.M.N., Mäntymäki, M.: Culture and student samples as moderators of continued IT usage: A meta-analysis of IS continuance literature. In: 15th Pacific Asia Conference on Information Systems (PACIS). AIS e-library, Brisbane (2011)

7. Davis, F.D.: Perceived usefulness, perceived ease of use, and user acceptance of information technology. MIS Quarterly 13(3), 319-340 (1989)

8. Bhattacherjee, A.: Understanding Information Systems Continuance: An ExpectationConfirmation Model. MIS Quarterly 25(3), 251-370 (2011)

9. Lee, J.-K., Lee, W.-K.: The relationship of e-Learner's self-regulatory efficacy and perception of e-Learning environment quality. Computers in Human Behavior 24, 32-47 (2008)

10. Liaw, S.S.: Investigating students' perceived satisfaction, behavioral intention, and effectiveness of e-learning: A case study of the Blackboard system. Computers \& Education 51, 864-873 (2008)

11. DeLone, W.H., McLean, E.R.: Information systems success: The quest for the dependent variable. Information Systems Research 3(1), 60-95 (1992)

12. Johnson, R.D., Hornik, S., Salas, E.: An empirical examination of factors contributing to the creation of successful e-learning environments. International J. Human-Computer Studies 66, 356-369 (2008)

13. Ellerman, H.H., Free, E.L.: A subject-controlled environment for paired associate learning. Journal of Computer-Based Instruction 17, 97-102 (1990)

14. Freitag, E.T., Sullivan, H.J.: Matching learner preference to amount of instruction: an alternative form of learner control. Educational Technology, Research, and Development 43, 5-14 (1995)

15. Northrup, P.: A framework for designing interactivity into Web-based instruction. Education Technology 41(2), 31-39 (2001)

16. Liaw, S.S., Huang, H.M., Chen, G.D.: An activity-theoretical approach to investigate learners' factors toward e-learning systems. Computers in Human Behavior 23, 1906-1920 (2007)

17. Leinder, D.E., Jarvenpaa, S.: The use of information technology to enhance management school education: a theoretical view. MIS Quarterly 19(3), 265-291 (1995)

18. Wang, M., Kang, M.: Cybergogy for engaged learning: a framework for creating learner engagement through information and communication technology. In: Hung, D., Khine, M.S. (eds.) Engaged Learning and Emerging Technologies, pp. 225-253. Springer, Netherland (2006)

19. Wegerif, R.: The social dimension of asynchronous learning networks. Journal of Asynchronous Learning Networks 2(1), 34-49 (1998)

20. Currin, L.: Feelin' groovy. eLearn Magazine (2003), http: / /www. elearnmag . org/subpage. cfm? section=articles\&articl e=10 -1 (retrieved May 6, 2011) 
21. Gatian, A.W.: Is user satisfaction a valid measure of system effectiveness? Information \& Management 26(3), 119-131 (1994)

22. Limayem, M., Hirt, S.G., Cheung, C.M.K.: How Habit Limits The Predictive Power Of Intention: The Case of Information Systems Continuance. MIS Quarterly 31(4), 705-737 (2007)

23. Sun, Y., Bhattacherjee, A., Ma, Q.: Extending technology usage to work settings: The role of perceived work compatibility in ERP implementation. Information \& Management 46, 351-356 (2009)

24. Hong, S.-J., Thong, J.Y.L., Tam, K.Y.: Understanding continued information technology usage behavior: A comparison of three models in the context of mobile internet. Decision Support Systems 42(3), 1819-1834 (2006)

25. Paechter, M., Maier, B., Macher, D.: Students' expectations of, and experiences in elearning: Their relation to learning achievements and course satisfaction. Computers \& Education 54, 222-229 (2010)

26. Straub, D.W., Boudreau, M.-C., Gefen, D.: Validation guidelines for IS positivist research. Communications of the Association for Information Systems 13, 380-427 (2004)

27. Ringle, C.M., Wende, S., Will, A.: Smart PLS 2.0 M3, University of Hamburg (2005), http: / / www. smartpls.de

28. Fornell, C., Larcker, D.F.: Evaluating structural equation models with unobservable variables and measurement error. Journal of Marketing Research 18(1), 39-50 (1981)

29. Nunnally, J.C.: Psychometric theory, 2nd edn. McGraw Hill, New York (1978)

30. Gefen, D., Straub, D.: A practical guide to factorial validity using PLS-Graph: Tutorial and annotated example. The Communications of the Associations for Information Systems 16(5), 91-109 (2005)

31. Woods, R., Jason, D.B., Hopper, D.: Hybrid structures: Faculty use and perception of webbased courseware as a supplement to face-face instruction. The Internet and Higher Education 7, 281-297 (2004)

32. Larsen, T.J., Sorebo, A.M., Sorebo, O.: The role of task-technology fit as users' motivation to continue information system use. Computers in Human Behavior 25, 778-784 (2009)

33. Cho, H., Gay, G., Davidson, B., Ingraffea, A.: Social networks, communication styles and learning performance in a CSCL community. Computers \& Education 49(2), 309-329 (2007)

34. Ortiz, M., Hoyos, J., Lopez, M.: The social networks of academic performance in a student context of poverty in Mexico. Social Networks 26(2), 175-188 (2004)

35. Dennis, A.R., Fuller, R.M., Valacich, S.J.: Rethinking media richness: towards a theory of media synchronicity. MIS Quarterly 32(3), 575-600 (2008)

36. Lim, H., Lee, S.-G., Nam, K.: Validating E-learning factors affecting training effectiveness. International Journal of Information Management 27, 22-35 (2007)

37. Dourish, P., Bly, S.: Portholes: Supporting awareness in a distributed work group. In: Proceeding of ACM Conference on Human Factors in Computing Systems, pp. 541-547. ACM, New York (1992) 